\title{
Disclosure of HIV-positive status to sexual partner and associated factors among ART users in Mekelle Hospital
}

This article was published in the following Dove Press journal:

HIVIAIDS - Research and Palliative Care

9 July 2015

Number of times this article has been viewed

\author{
Teklemariam Gultie' \\ Minichil Genet ${ }^{2}$ \\ Girum Sebsibie ${ }^{3}$ \\ 'Department of Midwifery, Arba \\ Minch University, Arba Minch, \\ Southern Ethiopia, Ethiopia; \\ ${ }^{2}$ Department of Nursing, Debre Tabor \\ Health Science College, Amhara \\ Region, Ethiopia; ${ }^{3}$ Department of \\ Nursing and Midwifery, Addis Ababa \\ University, Addis Ababa, Ethiopia
}

Purpose: The purpose of this study was to assess the disclosure of HIV-positive status and its associated factors to sexual partners among patients attending antiretroviral therapy (ART) clinic follow-up at Mekelle Hospital, Tigray, Ethiopia.

Patients and methods: An institution-based cross-sectional study was conducted at Mekelle hospital. Samples of 324 individuals were selected by using systematic random sampling techniques from July 1 until July 30, 2013. The data were collected by trained data collectors through a pretested semi-structured questionnaire. The collected data were cleaned, coded, entered, and analyzed using SPSS version 16.0 Windows program. Descriptive statistics and binary and multivariable regression analysis with $95 \%$ confidence interval was carried out and $P$-value less than 0.05 used to determine the significant association.

Results: A total of 324 people on ART care follow-up were interviewed with $100 \%$ response rate. The overall HIV status disclosure to sexual partner was $57.4 \%$. Among those who disclosed their HIV status, $58 \%$ of them told their partner after 1 month after diagnosis. The study showed that there is significant association between knowing HIV status of sexual partner (adjusted odds ratio $[\mathrm{AOR}]=16.69,95 \% \mathrm{CI}: 5.4,51.65)$, duration of HIV-related care follow-up (AOR =5.48, $95 \% \mathrm{CI}=2.17,13.80)$, and discussion before HIV testing $(\mathrm{AOR}=4.33,95 \% \mathrm{CI}=1.43,13.08)$, with HIV-positive status disclosure to sexual partner.

Conclusion: An HIV-positive status disclosure to a sexual partner in this study was lower than what was reported in other studies in Ethiopia. The duration of HIV-related care followup, knowing partner's HIV status, and prior discussion were the main factors that affected the practice of HIV-positive status disclosure to their sexual partners.

Keywords: cross sectional, institution based, systematic sampling, multivariate analysis

\section{Introduction}

The HIV/AIDS pandemic is one of the most destructive epidemics in the history of humankind. Globally, at the end of 2012, an estimated 35.3 million people were living with HIV, including 3.4 million children younger than 15 years of age. In the same year, there were 2.3 million new HIV infections worldwide, including 260,000 children younger than 15 years of age. The annual number of people newly infected with HIV rose in the Middle East and North Africa in 2012. The trends in AIDS-related death also differ, and in East Europe and Central Asia, the number of people dying from AIDS-related causes has increased more than fourfold between 2001 and 2012. ${ }^{1}$

One-third (34\%) of all people living with HIV in 2009 resided in the ten countries in Sub-Saharan Africa, and this included approximately $40 \%$ of all women living with HIV. It is estimated that $31 \%$ of the people newly infected with HIV and $34 \%$ of all
Department of Midwifery, Arba Minch University, PO Box 21 , Arba Minch, Southern Ethiopia, Ethiopia

Tel +251912786647

Fax +25। 468810279

Email tekledb2002@gmail.com 
the people dying from AIDS-related causes in the same year lived in these ten countries. ${ }^{2}$ HIV disproportionately affects women and young people. Women account for half (52\%) of the global adult prevalence and for $60 \%$ of the prevalence in Sub-Saharan Africa. ${ }^{3}$

In Ethiopia, the first case of HIV was reported in 1984. Since then, HIV/AIDS has become a major public health concern throughout the length and breadth of the country. According to the 2010 single point estimate, the estimated adult HIV/AIDS prevalence was $2.4 \%$, with an estimated 1.2 million people living with HIV/AIDS (PLWHA) in $2010 .{ }^{4}$

In Tigray Region, a total of 75,120 people are living with HIV/AIDS and there are an estimated 3,686 annual AIDS deaths, with the new HIV infection rate being 9,737. Of these people 19,200 need antiretroviral therapy (ART). ${ }^{5}$ In the region, the prevalence rate of HIV/AIDS was $1.8 \%$ in 2011 , less than the national figure. According to the Ethiopian demographic and health survey 2011 report, the prevalence of HIV among couples was $1.7 \%$, and it is a sad reflection to note that most of these couples do not mutually know their HIV status. ${ }^{6}$

The disclosure of HIV status to a sexual partner can have varying effects. It may motivate the partner to undergo voluntary counseling and testing (VCT), reduce risk behaviors, and increase acquisition of support and adherence to ART. ${ }^{7}$ However, on the contrary, it may cause blame, discrimination, abandonment, depression, loss of economic support, and disruption of family relationship. Therefore, it is easy to see why some patients may not disclose their HIV-positive status. ${ }^{8}$ It can also then have a negative effect on women's treatment outcomes, which have improved so much in recent years. There are several factors associated with facilitating disclosure of HIV status, such as not fearing negative outcomes of disclosure, having the habit of communicating with their partner about HIV, having initiated ART, and having seen other people publicly disclose their HIV status. ${ }^{9}$ In a study conducted in Tanzania, a close relationship with the person they told, the need for help, and advice from VCT care providers were the factors that facilitated the disclosure of the HIV status. ${ }^{10}$ In another study in Ethiopia, several factors were mentioned as a reason for disclosure of HIV status, such as educational status and ART status. ${ }^{11}$ So far, there is little known on HIV-positive status disclosure in Tigray Region. This study assessed the magnitude and the factors affecting disclosure of HIV-seropositive status to sexual partners among patients attending ART clinic follow-up at Mekelle Hospital, Tigray, Ethiopia.

\section{Material and methods}

\section{Study area, design, and period}

The study was conducted in Mekelle Hospital, using a cross-sectional study design, from July 1, 2013 until July 30, 2013.

\section{Sample size and sampling technique}

The sample size was calculated by using single population proportion formula. The assumption included $69 \%$ of female HIV-positive individuals disclosing their HIV-positive status to their sexual partners in southwest Ethiopia, 95\% level of confidence, and 5\% marginal error. The final sample size was $324{ }^{12}$ There were a total of 3,500 patients registered for ART care in the hospital. Approximately 80 patients attend the PLWHA clinic each day. We invited every third patient attending the clinic to participate in an interview until the required sample of 324 was recruited. As patients attended the clinic on a monthly basis, no patients presented twice during the recruitment period. The study included adult patients above the age of 18 years.

\section{Measurement}

For the interview, having a sexual partner was defined as any form of sexual relations including one-night stand, casual partner, intimate lover, and spouse (if married). Delayed disclosure was defined as disclosure of HIV status to sexual partner 1 month after diagnosis.

\section{Data collection and analysis}

A structured questionnaire was used on PLWHA attending the ART clinic, and data were collected by two nurses working within the clinic and supervised by the principal investigators. The questionnaire includes sociodemographic characteristics and the practice of HIV status disclosure of the study participants. The data collectors were trained for 1 day. The collected data were entered and analyzed using SPSS Version 16. Descriptive statistics and logistics regression was carried out to describe the variables and to determine their relationship with the outcome variable. Odds ratio with $95 \%$ CI (confidence interval) at $P<0.05$ was used to determine the significant level of association between predictors and outcome variable.

\section{Ethical consideration}

The study was approved by the ethical review committee of the College of Medicine and Health Science, Mekelle University. Oral consent was obtained from the study participants after detailed explanation about the objective of the 
study was explained in advance. Patients were interviewed in a strictly private room which was prepared near the ART clinic, and all the information collected from the respondents was kept confidential.

\section{Results}

\section{Sociodemographic characteristics of the study participants}

A total of 324 people on HIV/AIDS care follow-up were interviewed with $100 \%$ response rate. Among the participants 92.3\% (299) and 92\% (298) were urban residents and belonged to Tigray ethnic group, respectively. Female participants constituted $60.2 \%$ (195) of the study participants, and $45.1 \%$ (146) were in the age group of 35-44 years (Table 1).

\section{HIV-positive status disclosure}

The disclosure of their HIV-positive status was 57.4\% (186), and out of these, 58\% (108) of them delayed their

Table I Sociodemographic characteristics of the respondents

\begin{tabular}{|c|c|c|}
\hline Variables & Response option & $\%$ (number) \\
\hline \multirow[t]{2}{*}{ Residence } & Urban & 92.3 (299) \\
\hline & Rural & $7.7(25)$ \\
\hline \multirow[t]{2}{*}{ Ethnicity } & Tigray & $92.0(298)$ \\
\hline & Amhara & $8.0(25)$ \\
\hline \multirow[t]{2}{*}{ Sex } & Female & $60.2(195)$ \\
\hline & Male & $39.8(129)$ \\
\hline \multirow[t]{5}{*}{ Age } & $18-24$ & $4.3(14)$ \\
\hline & $25-34$ & $38.9(126)$ \\
\hline & $35-44$ & $45.1(146)$ \\
\hline & $45-54$ & $9.6(31)$ \\
\hline & $\geq 55$ & $2.2(7)$ \\
\hline \multirow[t]{6}{*}{ Occupation } & Daily worker & $34.6(112)$ \\
\hline & Governmental employee & $23.8(77)$ \\
\hline & House wife & $18.2(59)$ \\
\hline & Merchant & $17.0(55)$ \\
\hline & Farmer & $3.4(\mathrm{II})$ \\
\hline & Student & $3.1(10)$ \\
\hline \multirow[t]{5}{*}{ Marital status } & Married & $49.4(160)$ \\
\hline & Separated & $20.7(67)$ \\
\hline & Widowed & $13.0(42)$ \\
\hline & Single & II.7 (38) \\
\hline & Divorced & $5.2(17)$ \\
\hline \multirow[t]{4}{*}{ Religion } & Orthodox & 87.7 (284) \\
\hline & Muslim & $10.2(33)$ \\
\hline & Protestant & $\mathrm{I} .5(5)$ \\
\hline & Catholic & $0.6(2)$ \\
\hline \multirow[t]{5}{*}{ Educational status } & Illiterate & $24.0(78)$ \\
\hline & Primary school (Years I-4) & $9.0(29)$ \\
\hline & Primary school (Years 5-8) & $30.6(99)$ \\
\hline & Secondary school (Years 9-12) & $23.1(75)$ \\
\hline & Year 12 and above & $13.3(43)$ \\
\hline \multirow[t]{2}{*}{ Monthly income } & $\leq 500$ Ethiopian Birr & $55.2(179)$ \\
\hline & $>500$ Ethiopian Birr & $44.8(145)$ \\
\hline
\end{tabular}

status disclosure until 1 month after the initial diagnosis. Twenty-nine percent of the respondents disclosed their status within 1-2 months and 13.4\% after 6 months (Table 2).

\section{Factors associated with disclosure of HIV-positive status to sexual partner}

The binary logistic regression analysis showed that living together with a sexual partner $(\mathrm{COR}=9.01,95 \% \mathrm{CI}=5.40$, 15.02) and knowing HIV status of sexual partners ( $C O R=38.21$, $95 \% \mathrm{CI}=19.67,74.21$ ) were more likely to be factors that enabled study participants to disclose their HIV-seropositive status to their sexual partners. Educated participants ( $\mathrm{COR}=1.95,95 \% \mathrm{CI}=1.17,3.27)$ and married respondents $(\mathrm{COR}=8.95,95 \% \mathrm{CI}=5.34,15.01)$ were more likely to disclose their HIV status to sexual partner when compared to their counterpart.

This study indicated that being on ART treatment $(\mathrm{COR}=3.32,95 \% \mathrm{CI}=1.89,5.83)$, and having pretest counseling $(\mathrm{COR}=2.79,95 \% \mathrm{CI}=1.74,4.47)$ increased the likelihood of disclosing HIV status when compared with their counterparts. There was a clear association between socially related factors and disclosure to sexual partner. Being a member of HIV/AIDS association ( $\mathrm{COR}=2.09$, $95 \% \mathrm{CI}=1.29,3.37$ ), disclosure of HIV serostatus to peer groups and relatives $(\mathrm{COR}=2.16,95 \% \mathrm{CI}=1.36,3.43)$, having seen another person disclose their HIV status to the community $(\mathrm{COR}=2.38,95 \% \mathrm{CI}=1.52,3.75)$, and those in a stable relationship with their sexual partner before HIV test, were significantly associated with disclosure of HIV status to sexual partner.

After controlling multiple confounding factors by using multiple logistic regressions, variables that showed independent effect on disclosure of HIV status to sexual partner were identified. The result showed that patients who know their sexual partner's HIV status were more likely to disclose than those who did not knew their partner's HIV status (AOR

Table 2 HIV status disclosure and timing among ART clinic attendees at Mekelle Hospital, Tigray, Ethiopia

\begin{tabular}{lll}
\hline Disclosure status & $\begin{array}{l}\text { Yes, \% } \\
\text { (number) }\end{array}$ & $\begin{array}{l}\text { No, \% } \\
\text { (number) }\end{array}$ \\
\hline Disclosure to none & $23.8(77)$ & $76.2(247)$ \\
Disclosure to sexual partner & $57.4(186)$ & $42.6(138)$ \\
Disclosure to children & $15.7(5 \mathrm{I})$ & $84.3(273)$ \\
Disclosure to parents & $8.6(28)$ & $91.4(296)$ \\
Disclose within I month & $29(50)$ & \\
Disclose between I-6 months & $15.6(27)$ & \\
Disclose after 6 months & $13.4(23)$ & \\
\hline Abbreviation: ART, antiretroviral therapy. &
\end{tabular}


[adjusted odds ratio] $=16.69,95 \% \mathrm{CI}=5.4,51.65$ ). Those who had prior discussions before testing with their sexual partner disclosed their HIV status to sexual partner compared with those who did not discuss the situation ( $\mathrm{AOR}=4.3$, $95 \% \mathrm{CI}=1.43,13.08$ ). Based on different health care-related factors, only those who have had HIV-related care follow-up for more than 2 years were likely to disclose HIV-positive status to their sexual partner as compared with those who had less than 2 years follow-up $(\mathrm{AOR}=5.48,95 \% \mathrm{CI}=2.17$, 13.80) (Table 3).

\section{Discussion}

A disclosure of seropositive status to sexual partners enables couples to make informed reproductive health choices that may ultimately lower the number of unintended pregnancies among HIV-positive individuals, and reduce the risk of HIV transmission from mother to child. Similar to other studies, most of this study's subjects were in the younger age group which is due to the fact that HIV mostly affects young people.
The level of disclosure to a sexual partner was low (57.4\%), and about $33.4 \%$ of the participants disclosed their HIV status 1 month after diagnosis. It is lower than the findings in Jimma University Hospital (90.8\%), Hawasa Referral Hospital (85.7\%), Kemissie Northeast Ethiopia (93.1\%), and North West Ethiopia (69\%). ${ }^{12-16}$ The reasons for these variations might be due to the difference in the study population's sociodemographic characters as this study was conducted in clinical setting and included all PLWHA and who had a sexual partner at any time, whereas some of other studies included only current couples. In addition, the difference might be due to the fear of stigma in the society and rejection by their partners.

In this study, it was observed that prior discussion, knowledge about partner's status, and duration of HIV-related care follow-up were significantly associated with disclosure of HIV-positive status to sexual partner after adjusting for confounding variables. This finding is similar to the results of other studies. ${ }^{12,13,15,17-19}$ Communicating with one's partner prior to HIV testing is a key point in that it might help

Table 3 Predictors of HIV status disclosure to sexual partners among ART clinic attendees at Mekelle Hospital, Tigray, Ethiopia

\begin{tabular}{|c|c|c|c|c|}
\hline \multirow[t]{2}{*}{ Variables } & \multicolumn{2}{|l|}{ Disclose status } & \multirow[t]{2}{*}{ COR $(95 \% \mathrm{Cl})$} & \multirow[t]{2}{*}{ AOR $(95 \% \mathrm{Cl})$} \\
\hline & Yes, number (\%) & No, number (\%) & & \\
\hline \multicolumn{5}{|l|}{ Marital status } \\
\hline Married & $|3|(8 \mid .9)$ & $29(18.1)$ & $8.95(5.34,15.00)$ & \\
\hline Unmarried & $55(33.5)$ & $109(66.5)$ & 1 & \\
\hline \multicolumn{5}{|l|}{ Education status } \\
\hline Illiterate & 35 (44.9) & $43(55.1)$ & 1 & \\
\hline Literate & $|5|(6 \mid .4)$ & $95(38.6)$ & $1.95(1.17,3.27)$ & \\
\hline \multicolumn{5}{|c|}{ Living with partner } \\
\hline Yes & $136(8 \mathrm{I})$ & $32(19)$ & $9.01(5.40,15.02)$ & \\
\hline No & $50(32.1)$ & $106(67.9)$ & 1 & \\
\hline \multicolumn{5}{|c|}{ Knowing partner's status } \\
\hline Yes & I5I (9I.5) & $14(8.5)$ & $38.21(19.68,74.21)$ & $16.69(5.4,5 \mid .65)^{*}$ \\
\hline No & $35(22)$ & $124(78)$ & 1 & 1 \\
\hline \multicolumn{5}{|c|}{ Duration of HIV care } \\
\hline$\leq 2$ years & $65(43)$ & $86(57)$ & I & 1 \\
\hline$>2$ years & $|2|(69.9)$ & $52(30.1)$ & $3.08(1.95,4.87)$ & $5.48(2.17,13.80)^{*}$ \\
\hline \multicolumn{5}{|l|}{ Prior discussion } \\
\hline Yes & 122 (9I.7) & II (8.38) & $22.0(11.08,43.72)$ & $4.33(1.43,13.08)^{*}$ \\
\hline No & $64(33.5)$ & $127(66.5)$ & 1 & 1 \\
\hline \multicolumn{5}{|l|}{ Partner's relation } \\
\hline Smooth & I7I (67.3) & $83(32.7)$ & $4.81(2.49,9.30)$ & \\
\hline Disagreement & $15(30)$ & $35(70)$ & 1 & \\
\hline \multicolumn{5}{|l|}{ Pretest counseling } \\
\hline Yes & $140(66)$ & $72(34)$ & $2.80(1.74,4.50)$ & \\
\hline No & $46(4 I . I)$ & $66(58.9)$ & 1 & \\
\hline \multicolumn{5}{|l|}{ Member } \\
\hline Yes & 79 (68.7) & $36(3 \mid .3)$ & $2.09(1.30,3.38)$ & \\
\hline No & $107(5 \mid .2)$ & $102(48.8)$ & I & \\
\hline
\end{tabular}

Note: *Significant at $P$-value $<0.05$.

Abbreviations: ART, antiretroviral therapy; OR, odds ratio; $\mathrm{AOR}$, adjusted odds ratio; $\mathrm{Cl}$, confidence interval; $\mathrm{COR}$, crude odds ratio. 
individuals to anticipate a partner's reaction and would give them an opportunity to raise the issue and disclose their result. In these instances, disclosure may be easily discussed between partners as the conversation had been commenced before testing.

The duration of HIV care follow-up of more than 2 years was associated with disclosure of HIV status to sexual partner, and this finding is similar with other studies done in Jimma and Southern Ethiopia. ${ }^{13,14}$ This similarity could be the result of continuous counseling at each contact with health professionals and the use of behavior rehearsal technique, which is aimed at helping patients to develop healthy behaviors, including disclosure of HIV-positive status to sexual partner.

This study indicated that there is a relationship between ART initiation and disclosure of HIV status to sexual partner. This finding is similar to a qualitative study in Tanzania on PLWHA and also a study done in Mozambique, which showed that according to the Mozambique study 59.5\% males and $48.7 \%$ females disclose their HIV test result to sexual partner after 12 months of initiation of highly active ART. ${ }^{20-22}$ This discrepancy might be PLWHA on ART often reported feeling comfortable with their status. This was seen as a result of overcoming internalized feelings of shame, facilitating disclosure of HIV status. The other possible reason may be people on ART receive pre-ART counseling where disclosure is emphasized as a precondition and requirement for starting the treatment.

Consistent with other findings, in this study, married women were more likely to disclose HIV-positive status to sexual partners. ${ }^{23}$ This could be due to intimacy of partners, strength of their relationship, feeling of responsibility, and the confidence they have with each other, which would facilitate open communication, which in turn made them disclose their status. On the other hand, individuals residing together with their sexual partner were also associated with disclosure of HIV status, like other similar findings observed in Ethiopia and Rwanda. ${ }^{14,24}$

The finding of this study showed that there is an association between having normal, healthy relationship with their partner and HIV status disclosure to sexual partner, but it was not statistically significant like in other studies. ${ }^{15}$ This association might be due to the reason that in this study all types of sexual relations were included, unlike the other studies which only focused on long-term committed partners.

Discussion about HIV testing and test results with friends and relatives also facilitated disclosure of HIV-positive result to sexual partner. This finding is also similar to that of the Kemissie studies on PLWHA adult clinical service users. ${ }^{15}$ This might have helped individuals be strong and disclose their result to their partner. This may be because sharing ideas with friends and relatives gave strength for individuals spiritually as well as mentally, so that they could anticipate and accept the outcomes following disclosure.

However, the present study has some limitations, such as disclosure status was assessed through self-reporting questions, and this study utilized a cross-sectional study design which made it impossible to establish a causal relationship between the outcome and exposure variables.

\section{Conclusion}

The HIV-positive status disclosure to sexual partner in this study is low. Two-thirds of the study participants disclosed their HIV status to their sexual partners after 1 month, yet the majority of the respondents were sexually active. Generally, disclosure of HIV status to a sexual partner was strongly associated with prior discussion about HIV before testing, knowing the HIV status of their sexual partners, and duration of HIV-related care follow-up of more than 2 years.

\section{Acknowledgments}

The authors thank all the study participants and also Shirley Strong, a lecturer in Queens University, Belfast, for her language editing service.

\section{Author contributions}

MG, GS, and TG conceived the study, undertook statistical analysis, supervised the study, made the study design, carried out statistical analysis and contributed to the writing of the manuscript. All authors approved the submitted version of the manuscript.

\section{Disclosure}

The authors report no conflict of interests in this work.

\section{References}

1. WHO/UNAIDS/UNICEF [home page on the internet]. Geneva, Switzerland: Global HIV/AIDS response epidemic update and health sector progress towards universal access progress report [updated 2010 cited 2013 November 30]. Available from: http://www.who.int/hiv/pub/ progress_report2011/en/. Accessed June 20, 2013.

2. UNAIDS [home page on the internet]. Geneva, Switzerland: World AIDS day report [updated November 25, 2011; cited November 30, 2013]. Available from: http://www.cdc.gov/mmwr/preview/mmwrhtml/ mm6147a1.htm. Accessed June 15, 2013.

3. UNAIDS [home page on the internet]. Geneva, Switzerland: Global AIDS epidemic report. [Updated November 30, 2010, cited November 01, 2013]. Available from: http://www.unaids.org/sites/default/files/ en/media/unaids/contentassets/documents/epidemiology/2013/gr2013/ UNAIDS_Global_Report_2013_en.pdf. Accessed June 10, 2013.

4. FMOH/HAPCO [home page on the internet]. Addis Ababa, Ethiopia: Single point HIV prevalence estimate. [Updated July 04, 2007; cited July 05, 2010]. Available from: www.etharc.org/aidsineth/publications/ singlepointprev_2007.pdf. Accessed June 10, 2013. 
5. Tigray Health Bureau [home page on the internet]. Mekelle, Ethiopia: Profile report of Tigray regional health bureau. [Updated Dec 2011; cited January 14, 2011]. Available from: http://www.moh.gov.et/tigrayhb. Accessed June 21, 2013.

6. CSA Ethiopia [home page on the internet]. Addis Ababa, Ethiopia: Ethiopian Demographic and health survey. [Updated Feb 2011]. Available from: http://www.etharc.org/index.php/resources/download/ view.download/.../682. Accessed June 15, 2013.

7. Stirratt MJ, Remien RH, Smith A, Copeland OQ, Dolezal C, Krieger D. The role of HIV serostatus disclosure in antiretroviral medication adherence. AIDS Behav. 2006;10(5):483-493.

8. Larkins S, Reback CJ, Shoptaw S, Veniegas R. Methamphetaminedependent gay men's disclosure of their HIV status to sexual partners. AIDS Care. 2005;17:521-532.

9. Kadowa I, Nuwaha F. Factors influencing disclosure of HIV positive status in Mityana district of Uganda. Afr Health Sci. 2009;9(1):26-33.

10. Yonah G, Fredrick F, Leyna G. HIV sero-status disclosure among people living with HIV/AIDS in Mwanza, Tanzania. AIDS Res Ther. 2014;11:5.

11. Negesse D, Addis K, Awoke A, et al. HIV positive status disclosure and associated factors among children in North Gondar, Northwest Ethiopia. ISRN AIDS. 2012;2012:485720.

12. Deribe K, Wassie K, Lingerh, Yismaw D. Determinants and outcomes of disclosing HIV-sero positive status to sexual partners among women in Mettu and Gore towns, Illubabor Zone southwest Ethiopia. Ethiop $J$ Health Dev. 2005;19(2):126-131.

13. Kebede D, Kifle W, Mekitie W, Amaha Hand, Alemayehu A. Disclosure experience and associated factors among HIV positive men and women clinical service users in southwest Ethiopia. BMC Public Health. 2008;8:81

14. Taye G, Dereje H, Endrias M. HIV positive status disclosure to sexual partner among women attending ART clinic at Awassa University Referral Hospital, Ethiopia. Ethiop J Health Dev. 2010;24(1): 9-14.
15. Mohammed S, Belaynew W, Mengesha A. Disclosure of HIV positive result to a sexual partner among adult clinical service users in Kemissie District, Northeast Ethiopia. Afr J Reprod Health. 2012;16(1): 97-104.

16. King R, Katuntu D, Lifshay J, Packel L, Batamwita R, Nakayiwa S. Processes and outcomes of HIV serostatus disclosure to sexual partners among people living with HIV in Uganda. AIDS Behav. 2008;12(2): 232-243.

17. Elford J, Ibrahim F, Bukutu C, Anderson J. The role of ethnicity among people living with HIV in London. J Acquir Immune Defic Syndr. 2008;47:514-521.

18. Skunodom N, Linkins W, Culnane E, Prymanee J. Factors associated with nondisclosure of HIV infection status of new mothers in Bangkok. SE Asian J Trop Med. 2006;37:690-703.

19. Isaac K, Fred N. Factor's influencing disclosure of HIV positive status in Mityana district of Uganda. Afr Health Sci. 2009;9:1.

20. Simbayi L, Kalichman S, Strebel, A. Disclosure of HIV status to sex partners and sexual risk behaviours among HIV-positive men and women. Sex Transm Infect. 2007;83:29-34.

21. Pearson C. One year after ART initiation: psychosocial factors associated with stigma among HIV positive Mozambican. AIDS Behav. 2009;13:1189-1196.

22. Maria R, Alison W, Joanna B. A qualitative study on the impact of antiretroviral provision on the normalization of HIV in rural Tanzania and its implications for prevention. BMC Int Health Hum Rights. 2009;9:22.

23. WHO [home on the internet]: Geneva, Switzerland: Gender dimensions of HIV status disclosure to sexual partner: rates, barriers and outcomes: [updated Jan 2003]. Available from: http://www.who.int/gender/documents/women_and_girls/9241590734/en. Accessed June 20, 2013.

24. Keogh P, Allen S, Almedal C, Temahagili B. The social impact of HIV infection on women in Kigali, Rwanda: a prospective study. Soc Sci Med. 1994;38:1047-1053.
HIV/AIDS - Research and Palliative Care

\section{Publish your work in this journal}

HIV/AIDS - Research and Palliative Care is an international, peerreviewed open-access journal focusing on advances in research in HIV, its clinical progression and management options including antiviral treatment, palliative care and public healthcare policies to control viral spread. The journal welcomes original research, basic science,

\section{Dovepress}

clinical \& epidemiological studies, reviews \& evaluations, expert opinion \& commentary, case reports \& extended reports. The manuscript management system is completely online and includes a very quick and fair peer-review system. Visit http://www.dovepress.com/ testimonials.php to read real quotes from published authors. 